\title{
THE MONUMENTALITY OF MODERN ARCHITECTURE AS OBSERVED IN JAKARTA'S POLA BUILDING
}

\author{
${ }^{1}$ Lo Angela Irena. ${ }^{2}$ Dr. Bachtiar Fauzy, Ir., MT. \\ ${ }^{1}$ Student in the Bachelor's (S-1) Study Program in Architecture \\ at Parahyangan Catholic University \\ ${ }^{2}$ Senior lecturer in the Bachelor's (S-1) Study Program in Architecture \\ at Parahyangan Catholic University
}

\begin{abstract}
After the Indonesian people declared Independence on 17 August 1945, Ir. Soekarno had a modern vision and mission, namely that architecture could become a symbol of strength and power in a state. Therefore, various monumental building projects emerged, especially in Indonesia's capital Jakarta. One of these was the Pola building in Jakarta, a work of architecture designed by F. Silaban. The Pola building was actually constructed on top of Ir. Soekarno's former house and functioned as an exhibition space to display Overall Projects Planned for the First Eight Years 1961-1969 (PSBPTP).

The purpose of this study is to find out more about the architectural monumentality encountered in this research, to examine the concrete shape of the expression of this monumentality in the Pola building, and to determine the geometric elements, supporting the creation of this expression in this particular building. The research methods consist of the descriptive method, the analytical method and the interpretative method through the analysis of the physical and spatial data related to the observation of the building activities; interviews held with the building manager and the study made of the background literature on the object of study. The theory concerning architectural monumentality, the theory dealing with principles of arrangement (lay-out), the theory of geometrical elements and finally the theory concerning archetypes have been used to analyze the physical construction data regarding their monumentality.

The conclusion that may be drawn from this research is that the monumentality observed in the Pola building can be gleaned from the geometrical elements shaped like a striped rectangle as the composing element that contributes to its monumentality with its repetitive lay-out showing a static and balanced rhythm. The benefit of this research lies in the hope that it may make a positive contribution to the development of scientific knowledge in the field of architecture., and especially modern architecture in whose field this research has focused on the monumentality of buildings designed in the modern architectural style based on the physical condition of the building in question.
\end{abstract}

Keywords : Monumentalism, Architecture, Modern

\section{MONUMENTALITAS ARSITEKTUR MODERN PADA GEDUNG POLA DI JAKARTA}

\author{
${ }^{1}$ Lo Angela Irena. ${ }^{2}$ Dr. Bachtiar Fauzy, Ir., MT. \\ ${ }^{1}$ Mahasiswa S1 Program Studi Arsitektur Universitas Katolik Parahyangan. \\ ${ }^{2}$ Dosen Pembimbing S1 Program Studi Arsitektur Universitas Katolik Parahyangan.
}

\begin{abstract}
Abstrak- Setelah bangsa Indonesia menyatakan kemerdekaannya pada tanggal 17 Agustus 1945, Ir. Soekarno memiliki visi dan misi yang modern bahwa arsitektur dapat menjadi sebuah simbol kekuatan dan kekuasaan dalam suatu negara. Oleh karena itu, mulai muncul pembangunan proyek - proyek bangunan monumental khusunya di ibukota, Jakarta. Salah satunya adalah Gedung Pola di Jakarta karya dari F. Silaban. Gedung Pola merupakan bangunan yang dibangun di atas bekas rumah dari presiden Ir. Soekarno dan memiliki fungsi sebagai gedung pameran "Projek Semesta Berentjana Delapan Tahap Pertama 1961-1969".
\end{abstract}

\footnotetext{
${ }^{1}$ Corresponding Author: Loangelairena@gmail.com
} 
Tujuan studi ini adalah mengetahui monumentalitas arsitektur pada penelitian ini, mengetahui wujud ekspresi monumentalitas pada bangunan Gedung Pola di Jakarta, dan juga mengetahui elemen geometrik yang mendukung terciptanya ekspresi monumentalitas pada bangunan Gedung Pola di Jakarta.

Metode penelitian yang digunakan adalah metode deskriptif, metode analisis, dan metode interpretatif dengan cara menguraikan data fisik dan spasial bangunan yang dikaitkan dengan pengamatan aktivitas bangunan, wawancara dengan pengelola bangunan, dan data literatur tentang objek studi. Teori monumentalitas arsitektur, teori prinsip penataan, teori elemen geometri, dan teori arketipe digunakan untuk menganalisis data fisik bangunan mengenai monumentalitasnya.

Kesimpulan yang didapat dari penelitian ini adalah monumentalitas pada Gedung Pola yang ditunjukkan dari elemen geometri yang berbentuk berupa elemen bujur sangkar dengan garis sebagai elemen penyusun monumentalitasnya dengan penataan yang berulang menunjukkan irama yang statis dan seimbang. Manfaat dari penelitian ini adalah diharapkan dapat memberikan manfaat yang positif terhadap perkembangan ilmu pengetahuan di bidang arsitektur khususnya arsitektur modern, dimana pada penelitian ini terfokus pada monumentalitas bangunan arsitektur modern berdasarkan kondisi fisik bangunannya.

Kata-kata kunci : Monumentalitas, Arsitektur, Modern.

\section{PENDAHULUAN}

\subsection{LATAR BELAKANG PENELITIAN}

Ketika masa kepimpinan Ir. Soekarno paska kemerdekaan Indonesia tanggal 17 Agustus 1945, Arsitektur memiliki perubahan pandangan khususnya di mata Ir. Soerkarno. Jika awalnya arsitektur dipandang sebagai wujud pemersatu bangsa (nation building) namun arsitektur dapat juga menjadi wujud simbol kebanggan nasional (national pride). Karya arsitektur oleh Ir. Soekarno dimaknai bukan sekedar simbol persatuan nasional saja namun menjangkau sasaran yang lebih luas yaitu sebagai perwujudan kebanggan nasional atau national pride di mata dunia Internasional."

Studi ini mengangkat Gedung Pola sebagai kajian objek studi karena Gedung Pola termasuk dalam salah satu proyek bangunan monumental yaitu "Projek Mercusuar" tahun 1960. Gedung Pola merupakan karya arsitek kepercayaan Ir. Soekarno yaitu Friedrich Silaban. Gedung Pola berfungsi sebagai gedung pameran proyek "Pembangunan Nasional Semesta Berentjana Delapan Tahun Tahap I 1961-1969". Bangunan ini dibangun tepat dibelakang bekas rumah pribadi milik presiden pertama Indonesia Ir. Soekarno. Tepat di depan Gedung Pola terdapat monumen Tugu Petir yang merupakan posisi Ir. Soekarno dan Moh. Hatta membacakan naskah proklamasi untuk pertama kali.

Dari segi sejarah dan wujud fisik bangunan Gedung Pola mengindikasikan sebagai bangunan monumental yang dapat dipelajari melalui wujud arsitektur Gedung Pola yang dikaitkan dengan teori monumentalitas.

Pertanyaan penelitian dalam skripsi ini adalah:

1. Apa yang dimaksud dengan monumentalitas arsitektur pada penelitian ini?

2. Bagaimana wujud ekspresi monumentalitas pada Gedung Pola di Jakarta?

3. Elemen geometrik apa yang mendukung terciptanya ekspresi monumentalitas pada Gedung Pola di Jakarta?

\subsection{TUJUAN PENELITIAN}

Tujuan dari penelitian ini adalah:

1. Mengetahui apa yang dimaksud monumentalitas arsitektur dalam penelitian ini,

2. Mengetahui bagaimana wujud ekspresi monumentalitas pada Gedung Pola di Jakarta.

3. Mengetahui elemen geometrik apa saja yang mendukung terciptanya ekspresi monumentalitas pada Gedung Pola di Jakarta. 


\subsection{MANFAAT PENELITIAN}

Manfaat dari penelitian ini diharapkan dapat memberikan manfaat yang positif terhadap perkembangan ilmu pengetahuan di bidang arsitektur khususnya arsitektur modern, dimana pada penelitian ini terfokus pada monumentalitas bangunan arsitektur modern yang berdasarkan pada kondisi fisik bangunannya.

\subsection{OBJEK PENELITIAN}

Objek studi dalam penelitian ini adala Gedung Pola yang berlokasi di Jalan Proklamasi No. 56 (Jalan Pegangsaan Timur No. 56) Pesanggrahan, Menteng, Jakarta Pusat, Jakarta. Bangunan ini berfungsi sebagai gedung pameran. Gedung Pola terdiri dari enam lantai utama untuk ruang pameran dan satu lantai semi basement sebagai ruang servis dan parkir sepeda.

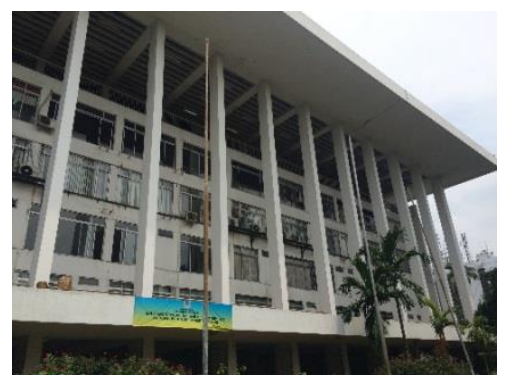

Figur 1. Gedung Pola, Jakarta

\subsection{METODOLOGI PENELITIAN}

Metodologi yang digunakan adalah deskripsi serta eksplanasi dengan mengeksplanasikan keadaan Gedung Pola Jakarta ketika sebelum renovasi pada era Soeharto, setelah itu analisis dengan menganalisa objek penelitian serta direlasikan dengan kajian teori mengenai monumentalitas arsitektur, teori ordering principle, teori archetypes, dan teori mengenai elemen geometri. Metodologi yang terakhir adalah metode interpretasi yakni interprestasi dari analisa yang di dapat sebagai wujud pemberian nilai makna pada objek penelitian untuk menghasilkan kesimpulan yang merupakan jawaban dari pertanyaan penelitian. Pengumpulan data ini berguna untuk mendapatkan data pendukung analisis, antara lain data tentang landscape, tata masa dan ruang, kegiatan, elemen arsitektur terutama pada fasad bangunan, dimensi serta fisik dan spasial pada Gedung Pola. Setelah data terkumpul maka dinalisis kondisi Gedung Pola sebelum renovasi dengan landasan teori dalam penelitian ini. Yang terakhir adalah tahap penyimpulan dari proses analisa untuk menjawab pertanyaan penelitian dan temuan penelitian sebagai kontribusi informasi menjawab permasalahan dan tujuan penelitian.

\section{KAJIAN TEORI}

\subsection{MONUMENTALITAS ARSITEKTUR Definisi dan Pengertian}

Monumentalitas dalam arsitektur adalah kualitas atau keadaan sebuah karya arsitektur sebagai sebuah bangunan monumental yang mengandung sebuah pesan atau makna didalamnya yang bertujuan sebagai simbol untuk mengenang sebuah peristiwa sejarah atau tokoh penting yang dapat dilihat dari aspek fisik bangunannya meliputi pola-pola yang terbentuk dari unsur atau elemen pelingkupnya. 


\section{Jenis Bangunan Monumental}

Bangunan monumental menurut Yoshinobu Ashihara terbagi menjadi dua jenis Primodial monumentality dan Complex Monumentality.

\section{Primodial Monumentality}

Sebuah objek arsitektur dapat mencapai monumentalitasnya jika objek tersebut secara jelas terisolasi dari objek-objek lain. Atribut dari jenis ini adalah kesederhanaan, kejelasan, kekebalan, dan bersifat umum.

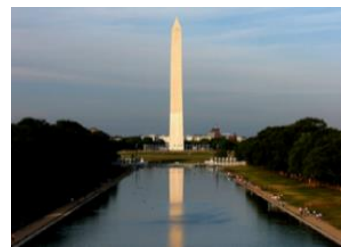

Figur 2. Primodial Monumentality

\section{Complex Monumentality}

Sebuah objek arsitektur dapat mencapai monumentalitasnya jika terdapat 'cluster' pada desain arsitektur. Objek arsitektur tidak berdiri sendiri seperti sebuah patung atau tugu melainkan berupa sebuah komplek yang terdiri dari beberapa monumen berada di satu tapak. Atribut dari jenis ini seperti ini bersifat kompleks, dapat dipenetrasi atau dimasuki, gelap dan terang.

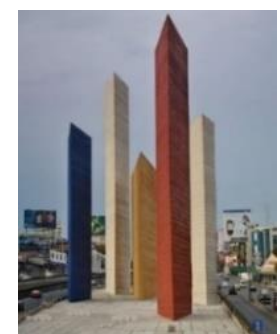

Figur 3. Complex Monumentality

\section{Teori Ordering Principle / Prinsip Penataan Terhadap Bangunan Monumental}

Teori ini merujuk pada keteraturan geometris dan penempatan suatu bentuk dan ruang agar menghasilkan suatu tatanan yang baik. Monumentalitas sebuah karya arsitektur dapat dilihat dari prinsip penataannya. Prinsip Penataan pada dasarnya dibagi menjadi enam bagian, yaitu: Sumbu, Simetri, Hirarki, Irama, Datum, dan Transformasi.

Sumbu

Sumbu merupakan sebuah garis imajiner yang dihasilkan oleh dua buah titik dalam suatu ruang dan juga sebagai unsur yang paling mendasar di dalam bidang arsitektur.

\section{Simetri}

Sebuah kondisi simetri tidak akan tercipta jika tidak ada keseimbangan antara polapola bentuk dan ruang yang setara pada sisi berlawanan sebuah garis atau bidang pembagi (Ching, 2008). Tatanan simetri selalu memiliki sumbu namun sebuah sumbu tidak selalu mencerminkan tatanan yang seimbang.

\section{Hierarki}

Suatu tatanan hirarki menunjukkan adanya perbedaan tingkat kepentingan bentuk dan ruang di dalam suatu komposisi (Ching, 2008). Untuk dapat menentukan nilai hirarki di dalam suatu komposisi, suatu bentuk atau ruang harus dibuat berbeda 
yakni dengan dimensi, tata letak, elemen pelingkupnya, derajat ketertutupan, dan lain sebagainya.

$>$ Irama

Irama memiliki peranan mengatur bentuk dan ruang di dalam arsitektur dengan cara pengulangan elemen atau motif pada interval yang beraturan maupun tidak (Ching, 2008). Irama berkaitan dengan repetisi satau pengulangan.

Datum

Datum adalah suatu tatanan yang berfungsi merangkul atau menggabungkan beberapa elemen menjadi satu kesatuan dalam sebuah komposisi. Datum dapat berupa bentuk garis, bidang, atau volumetris

$>$ Transformasi

Transformasi adalah suatu tatanan yang mengubah bentuk atau ruang menjadi bentuk yang berbeda dengan bentuk asalnya. Proses transformasi melewati serangkaian manipulasi dan permutasi terpisah tanpa menghilangkan identitas atau konsepnya.

Karakter bangunan monumental dari prinsip penataannya adalah tatanannya yang simetri dan memiliki hierarki.

\section{Wujud Ekspresi Bangunan Monumental}

Wujud ekspresi bangunan monumental dibagi menjadi lima aspek, yaitu: tata letak, lingkungan, konstruksi, material, dan elemen-elemennya.

\section{Tata letak}

Sebuah bangunan dikatakan monumental jika tata letak bangunan terhadap tapak menunjukkan menguasai tapak. Umumnya diletakkan jauh dari pencapaiannya agar pengamat bangunan dapat merasakan monumentalitasnya dari kejauhan. Bangunan monumental yang baik harus dapat dicapai dari segala arah.

\section{Lingkungan}

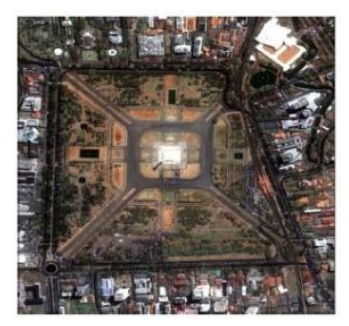

Figur 4. Tata Letak

Sebuah bangunan dapat dirasakan monumentalitasnya jika bangunan tersebut memiliki skala yang besar dan lingkungan yang mendukung terciptanya monumental pada bangunan tersebut, yatu dengan dikelilingi oleh bangunan yang bertingkat lebih rendah dibanding objek monumentalnya dan vegetasi yang tidak menganggu pandangan menuju bangunan monumental.

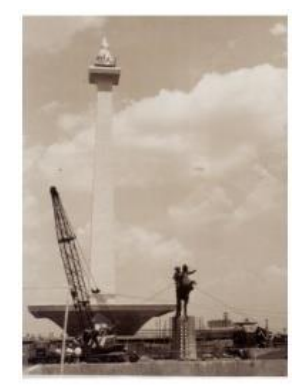

Figur 5. Lingkungan 


\section{Konstruksi}

Sebuah bangunan monumental erat kaitannya dengan bangunan yang megah, unik, dan orisinil. Oleh karena itu sistem struktur berperan pula dalam membentuk monumentalitas sebuah bangunan. Penggunaan sistem struktur yang terbaru dan beda dengan lainnya.

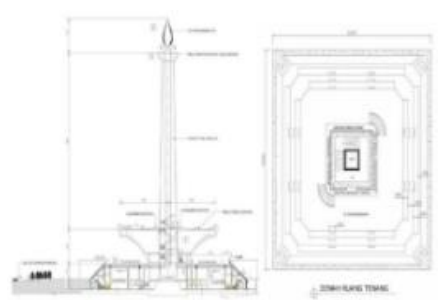

Figur 6. Konstruksi

Material

Sebuah objek monumental selalu identik dengan bangunan yang tahan lama dan karya arsitektur monumental selalu dikaitkan dengan biaya. Semakin mahal sebuah karya arsitektur maka akan semakin monumental karena kemegahannya. Oleh karena itu, sebuah objek arsitektur yang monumental dalam menunjukkan monumentalitasnya, maka banyak bangunan monumental yang menggunakan bahan material yang mahal dan kuat untuk menambah kemegahan dan keagungan pada tampilan bangunan.

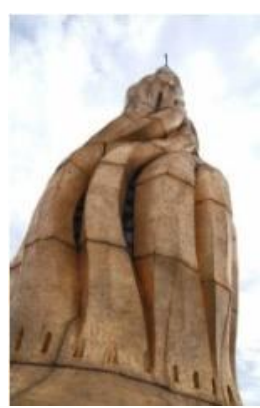

Figur 7. Material

\section{Elemen-elemen}

Elemen-elemen yang dimaksud adalah elemen pelingkup dan elemen ornamen yang terdapat pada sebuah objek arsitektur monumental seperti pola lantai, dinding, atap, kolom, bukaan, plafon, dekorasi dan sebagainya. Bangunan monumental erat kaitannya dengan tatanan elemennya yang seimbang dan adanya hierarki dan megah yang ditunjukkan dari elemen-elemen bangunannya.

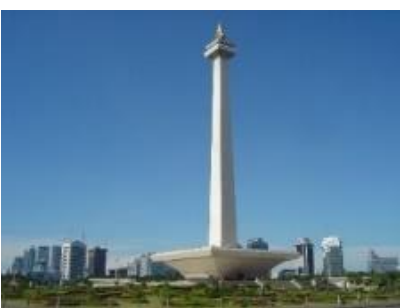

Figur 8. Elemen 


\section{Elemen Geometri}

Elemen geometri dalam arsitektur adalah elemen-elemen dasar yang membentuk pelingkup sebuah bangunan dan menghasilkan sebuah komposisi estetis tertentu pada bangunan tersebut. Elemen-elemen geometri dasar berupa lingkaran, kotak, dan segitiga yang dikomposisikan dengan berbagai macam cara, misalnya diputar (twist), ditumpuk (overlay), dipindah (move), pengulangan (copy), substraksi (subtract), dan adisi (addition). Elemen geometris pada sebuah karya arsitektur juga dapat menentukan monumentalitas dari objek arsitektur tersebut.

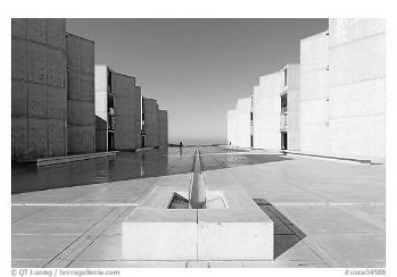

Figur 9. Elemen Geometri

\section{Archetypes}

Archetypes diidentifikasikan sebagai tiga bagian yaitu lantai, dinding dan atap sebagai elemen yang dapat dialami dalam kaitannya dengan tubuh melalui gerak (motion), bobot (weight) dan substansi (substance). Hasil pengalaman ini kemudian terkait dengan kualitas dan relasi keseharian antara karya arsitektur dan penggunanya yang akhirnya membentuk kualitas esensial bermukim yang baik.

\section{Profil Arsitek Silaban}

Karya-karya arsitektur Friedrich Silaban menunjukkan citra pemikiran arsitek modern yang dimodifikasi dengan pemikiran Silaban sendiri yang memperhitungkan faktor lokasi, bentuk yang lugas, sederhana, dan geometris. fungsional secara ruang dan elemen pelingkupnya namun tetap estetis. Keteguhannya dalam memegang prinsipnya membawa rancangannya menjadi karya berpengaruh terhadap perkembangan arsitektur monumental di Indonesia.

\section{ANALISA}

\subsection{ARSITEKTUR BANGUNAN GEDUNG POLA}

\section{Tata Letak}

Posisi bangunan Gedung Pola memiliki sumbu terhadap letak Rumah Proklamasi yang saat ini telah rata dengan tanah dan diganti dengan Tugu Petir sebagai penanda posisi Ir. Sukarno berdiri ketika membacakan naskah proklamasi. Akses utama menuju bangunan Gedung Pola melalui Jalan Bonang dan Jalan Penataran, sedangkan akses pejalan kaki melalui Jalan Proklamasi. Entrance bangunan Gedung Pola tediri dari dua yaitu entrance pada area depan melalui Jalan Penataran dan entrance pada area belakang melalui Jalan Bonang. Akses Jalan Proklamasi tersebut menghubungkan antara Tugu Petir dengan massa bangunan Gedung Pola. Jadi, Bangunan Gedung Pola dapat diakses dari semua sisi. 


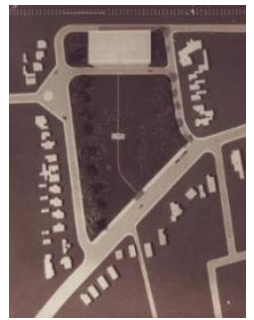

Figur 10. Tata Letak Gedung Pola

\section{Bentuk dan Massa}

Bangunan Gedung Pola merupakan sebuah bangunan unit tunggal berdenah persegi panjang. Wujud bangunan Gedung Pola merupakan penerapan dari gaya arsitektur modern yang disebut dengan Stripped Classicism yang dipadukan dengan Arsitektur Tropis. Ekspresi gaya arsitektur Stripped Classicism pada Gedung Pola ditunjukkan dari jajaran kolom-kolom raksasa yang berfungsi sebagai penopang beranda dan atap Gedung Pola dan bentuk massa Gedung Pola yang geometris. Ekspresi arsitektur tropis pada bangunan Gedung Pola ditunjukkan dengan penggunaan teritis atap yang lebar sebagai penangkal panas matahari dan tempias hujan.

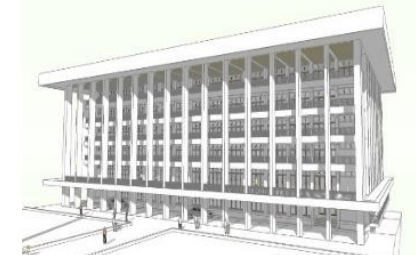

Figur 11. Bentuk dan Massa

\section{Zoning dan Pola Tata Ruang}

Zoning pada Gedung Pola terbagi menjadi dua zonasi yaitu publik dan servis. Publik untuk ruang pameran dan servis untuk fungsi servis. Ruang pada Gedung Pola berbentuk linier dengan perletakan sirkulasi di pinggi-pinggir sedangkan di tengah terdapat area void. Ruangan ditata dengan mezzanine untuk memberikan kesatuan antar lantainya.

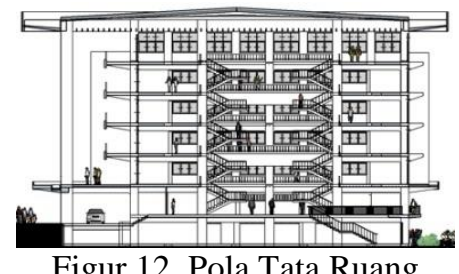

Figur 12. Pola Tata Ruang

\section{Elemen-elemen}

elemen pada bangunan Gedung Pola terdiri dari atap (atap dan plafon), dinding (jendela, pintu, kerawang, dinding, railing), dan lantai (pola lantai)

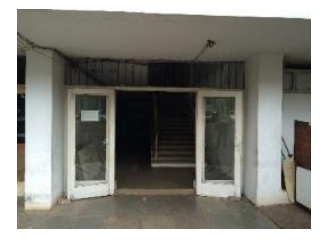

Figur 13. Elemen Pintu

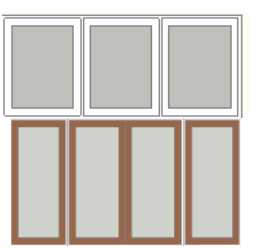

Figur 14. Elemen Bukaan

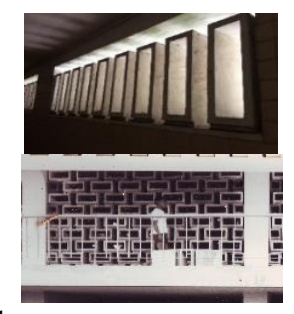

\section{.}




\subsection{MONUMENTALITAS ARSITEKTUR MODERN PADA GEDUNG POLA DI JAKARTA}

Dalam menganalisa bangunan Gedung Pola mengenai Monumentalitas arsitektur pada Gedung Pola maka akan dibagi menjadi menjadi beberapa bagian, yaitu sebagai beirkut:

$>$ Tata Letak

Karakter monumentalitasnya adalah bangunan Gedung Pola terlihat menguasai tapak karena posisinya di tengah-tengah tapak dan letaknya yang jauh dari pencapaian atau lebih menjorok ke dalam tapak sehingga memunculkan ekspresi monumentalitasnya didukung dengan tinggi bangunan Gedung Pola setinggi 23.50 meter. Tinggi bangunan Gedung Pola yang lebih tinggi dari Tugu Petir yang memiliki tinggi 17 meter menunjukkan hierarki Gedung Pola yang lebih tinggi dari Tugu Petir.

Tata letak bangunan Gedung Pola memiliki axis simetris yang kuat terhadap letak rumah Ir. Soekarno yang diganti menjadi Tugu Petir sehingga jika dilihat massa bangunan sejajar dengan jalur rel kereta api yang ada di belakang Gedung Pola, bukan sejajar dengan Jalan Pegangsaan Timur (Jalan Proklamasi). Hal ini menunjukkan bahwa bangunan Gedung Pola memiliki hubungan dengan sejarah Indonesia pasca kemerdekaan 1945.

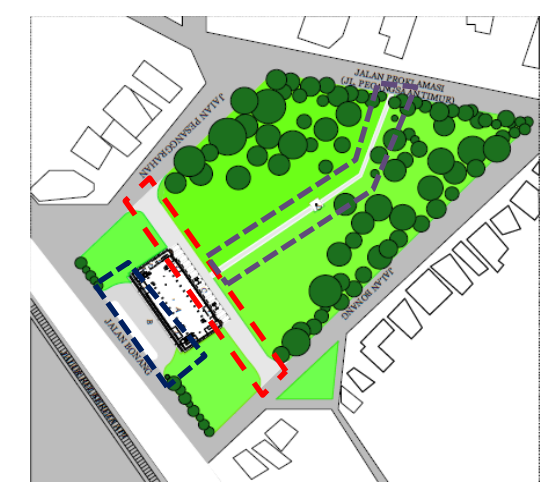

Figur 15. Tata Letak Massa dan Akses pada Gedung Pola

\section{Lingkungan}

Lokasi bangunan Gedung Pola berada di atas tanah bekas rumah Presiden Pertama Republik Indonesia Ir. Sukarno dan merupakan tempat dibacakannya naskah proklamasi Indonesia pertama kali. Bangunan Gedung Pola dapat diketahui oleh banyak orang karena lokasinya yang memiliki nilai sejarah bagi Indonesia juga Gedung Pola berada di pusat kota Jakarta yaitu daerah Menteng, Jakarta Pusat. Jadi, lokasi bangunan Gedung Pola termasuk kawasan yang strategis.

Kawasan Menteng merupakan kawasan yang diperuntukan untuk fungsi hunian di kawasan Jakarta Pusat, Jakarta. Dengan demikian bangunan yang ada di lingkungannya didominasi dengan bangunan hunian bertingkat rendah. Dengan tinggi bangunan Gedung Pola yang lebih tinggi dari bangunan di sekitar menjadikan Gedung Pola menjadi bangunan monumental diantara bangunan yang ada disekitarnya. Dengan tinggi 23.50 meter, Gedung Pola dirancang agar bangunan juga dapat terlihat dari arah jembatan rel kereta api.

Hierarki pada lingkungan Gedung Pola yang didominasi bangunan rendah menjadikan bangunan Gedung Pola sebagai bangunan yang monumental karena bentukan arsitekturnya yang menonjol dan skalanya. Dengan demikian hierarki 
lingkungan sekitar Gedung Pola paling tinggi terdapat pada bangunan Gedung Pola.

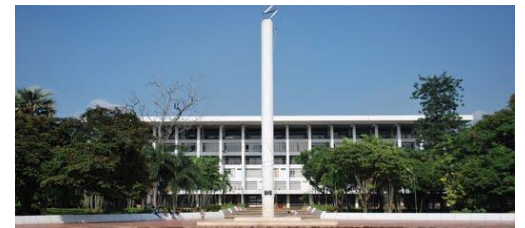

Figur 16. Vegetasi pada Tapak Gedung Pola

Desain lansekap Gedung Pola dirancang halaman rumput dengan tanaman dan pohon ditata pada sisi kiri dan kanan yang berfungsi sebagai pengarah pengamat menuju Gedung Pola. Rancangan lansekap tersebut bertujuan agar penglihatan pengamat terhadap bangunan Gedung Pola tidak terganggu dengan vegetasi yang ada pada tapak dan fokus hanya pada bangunan Gedung Pola sebagai bangunan monumental.

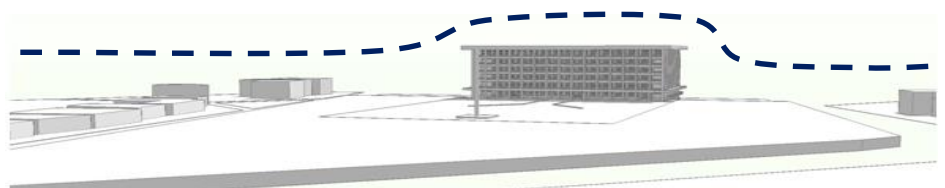

Figur 17. Hierarki Gedung Pola terhadap Lingkungan

Pengamat dapat melihat bangunan secara keseluruhan bila sudut pandangannya $27^{\circ}$, atau dalam perbandingan jarak bangunan dibagi dengan tinggi bangunan sama dengan 2. Jarak minimal untuk mengamati Gedung Pola secara keseluruhan adalah $\mathrm{D}=2 \times \mathrm{H} ; \mathrm{D}=2 \times 20.90 \mathrm{~m} ; \mathrm{D}=41,80 \mathrm{~m}$. Hasilnya adalah jarak yang dibutuhkan minimal untuk mengamati Gedung Pola secara keseluruhan 41.80m. Jarak bangunan Gedung Pola berjarak sekitar 200 meter dari Jalan Proklamasi dan kurang lebih 48,10m dari sisi samping tapak.

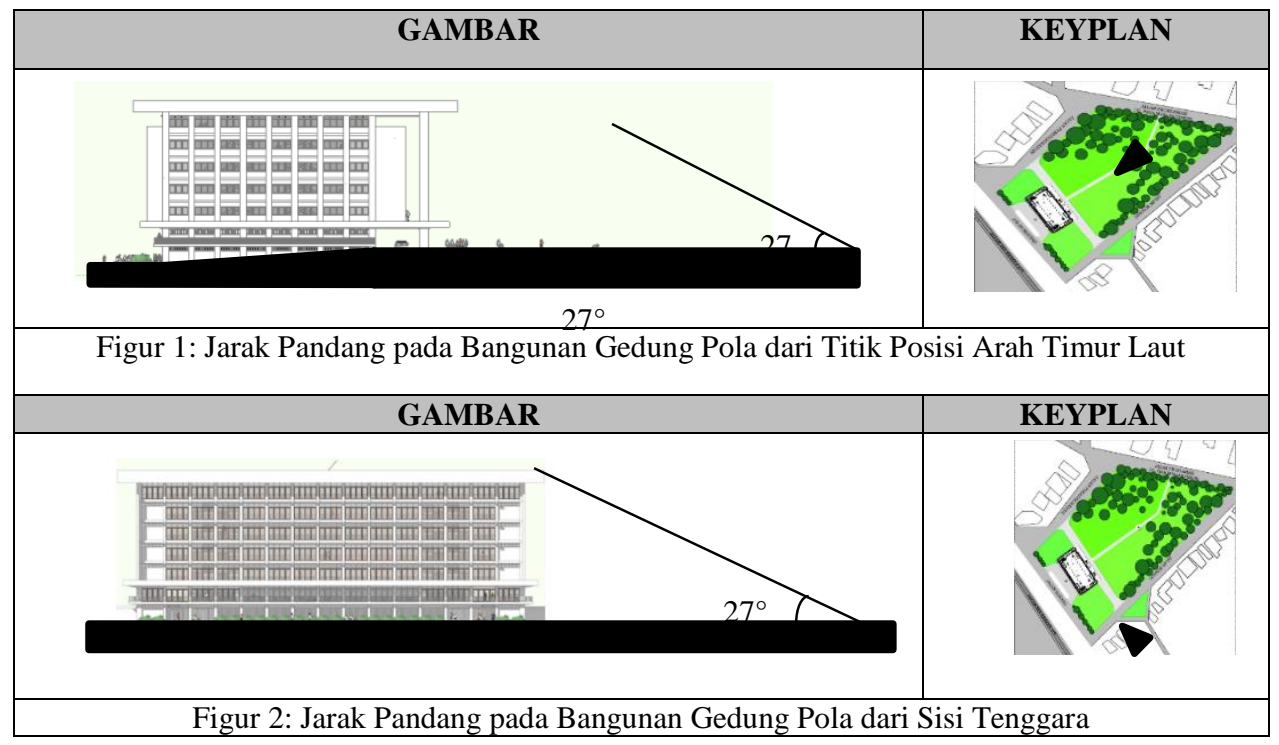

Dilihat dari aspek lingkungan, bangunan Gedung Pola memiliki kondisi lingkungan yang mendukung monumentalitasnya yaitu lokasi bangunan Gedung Pola yang strategis berada di pusat kota Jakarta, berada dikawasan bangunan bertingkat rendah yaitu kawasan permukiman, dan posisi massa Gedung Pola yang menjauhi jalan menimbulkan citra monumental dari kejauhan. 


\section{Konstruksi}

- Struktur Bangunan: Struktur yang digunakan pada desain Gedung Pola menggunakan sistem struktur Portal. Sedangkan sistem konstruksi atap menggunakan sistem Kantilever. Sistem struktur tersebut termasuk sistem struktur yang baru bagi arsitektur Indonesia pada konstruksi bangunan pada saat itu. Dalam sistem struktur terdapat hierarki yang menunjukkan tingkatan ruang.

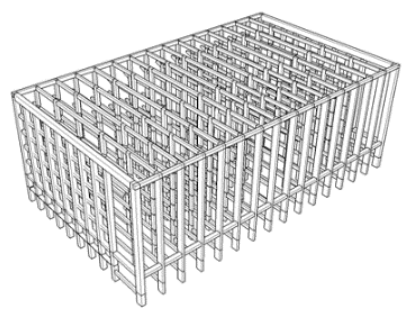

Figur 20. Sistem Struktur Gedung Pola

Hierarki tertinggi ditunjukkan pada kolom-kolom raksasa yang memiliki bentuk yang berbeda diantara kolom-kolom luar pada bangunan Gedung Pola yaitu berbentuk raksasa dengan ketinggian 20.50 meter. Irama atau pengulangan pada sistem konstruksi pada bangunan Gedung Pola tampak dari penggunaan grid $4 \mathrm{~m}$ x $3 \mathrm{~m}, 4 \mathrm{~m} \times 7 \mathrm{~m}$ dan $4 \mathrm{~m} \times 14 \mathrm{~m}$. Permainan jarak antar kolom pada bangunan Gedung Pola memunculkan kesan statis pada tiap lantainya namun dinamis secara keseluruhan.

- Struktur Tangga: Tangga sebagai transportasi vertikal pada bangunan Gedung Pola terdapat dua jenis tangga yaitu tangga kantilever dan tangga biasa. Tangga kantilever tersebut menunjukkan adanya kemajuan teknologi struktur khususnya pada rancangan tangga pada Gedung Pola. Tangga kantilever menunjukkan kemajuan sistem kontruksi pada bangunan di Indonesia. Hierarki nampak pada perbedaan konstruksi tangga yang menunjukkan perbedaan tingkatan ruang. Tangga kantilever yang menerus dari lantai satu sampai dengan lantai mezzanine tiga memiliki bentuk tangga $\mathrm{U}$ sedangkan tangga biasa yang menyambungkan lantai semi basement dengan lantai satu. Memiliki bentuk tangga biasa pada umumnya. Hal ini menunjukkan bahwa hierarki pada tangga kantilever pada bangunan Gedung Pola lebih tinggi di banding tangga biasanya

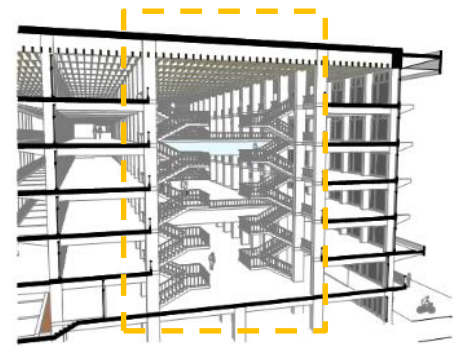

Figur 21. Tangga Kantilever pada Gedung Pola

Sistem konstruksi menunjukkan bangunan Gedung Pola sebagai bangunan yang monumental karena sistem struktur portal yang digunakan pada bangunan Gedung Pola maupun struktur tangga yang berupa kantilver. Rancangan sistem struktur yang unik dan berbeda dengan bangunan-bangunan sekitar menunjukkan hierarki bangunan Gedung Pola lebih tinggi dibanding bangunan sekitarnya dilihat 
dari sistem strukturnya. Keunikan sistem struktur tersebut yang membuat bangunan Gedung Pola terlihat monumental dari aspek strukturnya.

Material

Material beton sangat dominan pada Gedung Pola, terlihat dari strukturnya yang menggunakan beton, atap menggunakan dak beton, dan elemen ornamen seperti kerawang menggunakan material beton. Sedangkan material besi digunakan untuk kerawang dan railing dalam ruang bangunan Gedung Pola, railing tangga, dan railing balkon. Penggunaan bahan lokal terlihat dari material kayu yang digunakan untuk bukaan jendela dan pintu, plafon, dan railing. Dominasi oleh material beton menunjukkan bahwa beton sebagai hierarki tertinggi pada segi material pada bangunan Gedung Pola. Material beton juga terlihat sebagai unsur yang menyatukan bangunan Gedung Pola karena dari elemen, konstruksi, dan atap bangunan Gedung Pola menggunakan material beton.

\section{Elemen-Elemen}

- Kepala Bangunan

- Atap

Atap bangunan Gedung Pola berbentuk atap dak beton dengan teritis lebar dan kemiringan atap sebagai cerminan arsitektur modern yang memperhatikan konteks lingkungan iklim tropisnya dan tidak terikat dengan arsitekur tradisional. Bentuk atap datar berbentuk geometri persegi panjang dengan material beton. Bentuk atap yang berbentuk geometri menunjukkan adanya tatanan yang simetris dan kaku. Atap dak beton yang menaungi keseluruhan bagian bangunan Gedung Pola menunjukkan peran atap sebagai unsur datum yang menyatukan semua elemen pada bangunan Gedung Pola

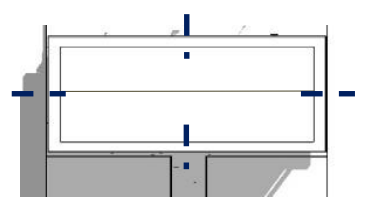

Figur 3: Tatanan Sumbu Simetris pada

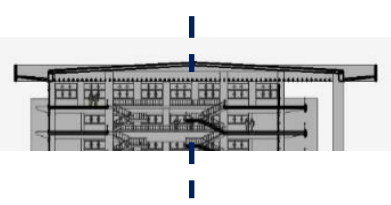

Figur 4: Tatanan Sumbu Simetri pada Bentuk

- Plafon

Plafon yang digunakan pada bangunan Gedung Pola terdiri dari tiga jenis, yaitu: plafon multiplek, plafon eternit, dan plafon balok-balok kayu. Dari penataan plafon, terlihat unsur simetris dan sumbu dalam tatanannya. Dari bentuk plafon, material plafon, dan dimensi plafon menunjukkan hierarki tertinggi terdapat pada plafon balok-balok kayu karena plafon balok kayu tersebut menghiasi empat ruang sekaligus, sedangkan plafon multiplek dan plafon eternit masing-masing hanya terdapat pada satu ruangan saja. 


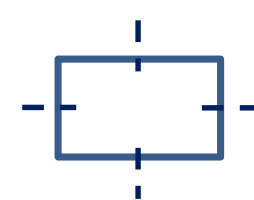

Figur 5: Sumbu Simetri pada Plafon Multiplek Ruang Tengah Lantai Satu

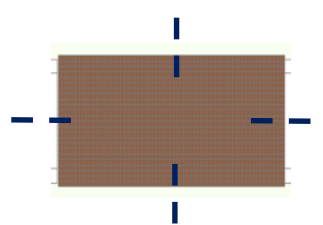

Figur 6: Sumbu Simetri pada Plafon Eternit Ruang Tengah Lantai Dua

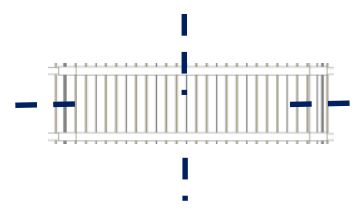

Figur 7: Sumbu Simetri pada Plafon Balok Kayu Ruang Tengah Lantai Tiga dan Lantai Mezzanine Tiga

- Badan Bangunan

- Kolom

Kolom-kolom raksasa pada bagian depan bangunan Gedung Pola menunjukkan hierarki tertingginya karena terletak pada area penerima dengan bentuknya yang ramping dan tinggi memberikan kesan megah dan indah yang dihasilkan dari wujud tatanannya dan efek bayangan yang muncul pada bangunan Gedung Pola

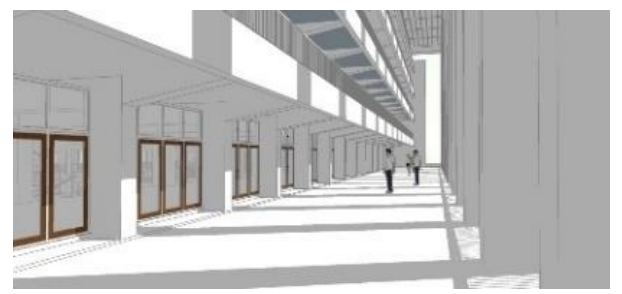

Figur 27. Efek Pembayangan Kolom-Kolom Raksasa

\section{- Jendela dan Kerawang}

Jendela dan Kerawang yang digunakan pada bangunan Gedung Pola menunjukkan prinsip penataan yang repetisi atau pengulangan dan simetri pada fasad bangunan. Bentuk jendela pada sisi depan bangunan Gedung Pola sama dengan sisi belakang bangunan Gedung Pola. Sedangkan jendela pada sisi samping kanan bangunan Gedung Pola sama dengan sisi samping kirinya. Hal ini menunjukkan keseimbangan antara depan dan belakang juga antara kiri dan kanan.

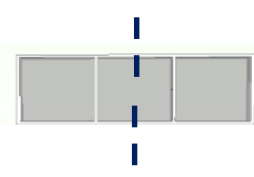

Figur 8: Sumbu Simetri pada Jendela Fixed Tampilan Samping Gedung Pola

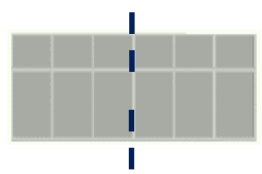

Figue 10: Sumbu Simetri pada Jendela Fixed Kaca Patri Lantai Satu Tampilan Depan dan Belakang Gedung Pola

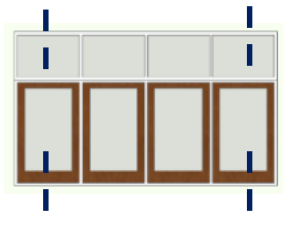

Figur 9: Sumbu Simetri pada Jendela Fixed dengan Satu Daun Pintu Tampilan Depan Gedung Pola

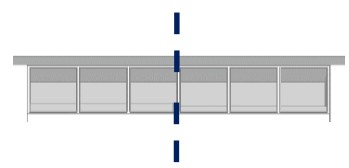

Figur 11: Sumbu Simetri pada Jendela Fixed pada Tampilan Depan dan Belakang Gedung Pola 


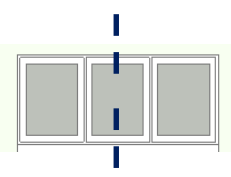

Figur 12: Sumbu Simetri pada Jendela Center Pivot pada Tampilan Samping Gedung Pola

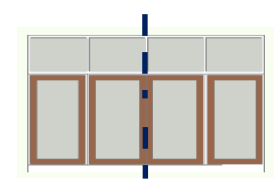

Figur 13: Sumbu Simetri pada Jendela Satu Rangkap dengan Dua Daun Jendela pada Tampilan Belakang Gedung Pola

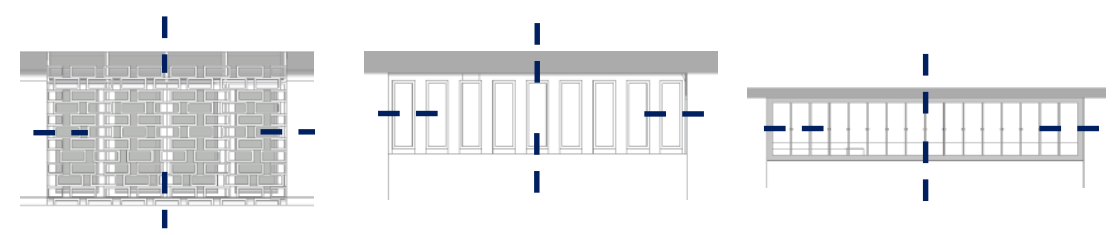

Figur 14: Simetri pada Kerawang Beton Lantai Satu Tampilan Belakang Gedung Pola

- Pintu

Pintu yang terdapat pada area penerima baik itu sisi depan maupun depan bangunan memiliki bentuk yang berbeda dengan pintu untuk servis. Hal ini bertujuan untuk menunjukkan hierarki ruang yang lebih tinggi yaitu ruang utama lebih tinggi hierarkinya dibanding ruang servis. Tatanan simetri sebagai ekspresi dari bangunan monumental ditunjukkan juga pada elemen bentuk dari pintu yang simetris.

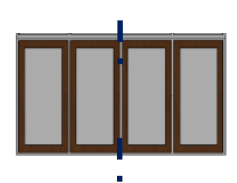

Figur 15: Tatanan Simetri pada Pintu Tipe A pada Bangunan Gedung Pola

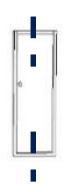

Figur 16: Tatanan Simetri pada Pintu Tipe B pada Bangunan Gedung Pola

- Tangga dan Railing

Hierarki tangga terlihat dari material yang digunakan sebagai pelapis tangga dan bentuk tangganya. Seperti yang telah dijelaskan pada poin sebelumnya bahwa lantai teraso pada tangga kantilever memiliki warna lebih gelap dibanding lantai pada tangga biasa. Hal ini menandakan bahwa tangga kantilever memiliki hierarki lebih tinggi dari tangga biasa.

Railing pada tangga, railing balkon, railing tiap lantai menggunakan material besi dengan bentuk persegi panjang menampilkan unsur geometri yang menunjukkan tatanan simetris. Handrail menggunakan material kayu. Datum terlihat dari kesamaan bentuk dan dimensi railing yang sama pada tiap lantai maupun di balkon Gedung Pola. 


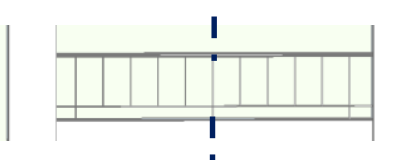

Figur 17: Tatanan' Sumbu Simetri pada Railing Dalam Gedung Pola Jakarta

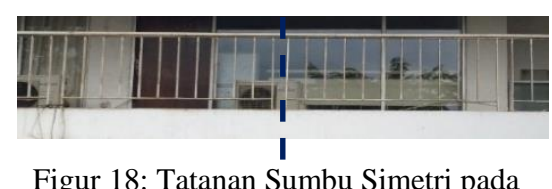

Figur 18: Tatanan Sumbu Simetri pada Railing Balkon Gedung Pola Jakarta

- Kaki Bangunan

Pada area penerima lantai satu memiliki dimensi lantai lebih kecil dan tekstur yang halus dan warna yang cerah yang menunjukkan area penerima yang utama. Berbeda dengan area penerima lantai semi basement yang memiliki dimensi lantai lebih besar, warna lebih gelap, dan terkstur lebih kasar. Sedangkan pada ruang dalam bangunan Gedung Pola hierarki ruang dibedakan dari dimensi ukuran lantai teraso. Pada lantai satu, dua, dan tiga memiliki dimensi lantai lebih besar dari dimensi lantai teraso lantai mezzanine satu, mezzanine dua, dan mezzanine tiga. Hal ini menunjukkan hierarki ruang lantai satu, dua dan tiga lebih tinggi dari ruang lainnya. Pada area parkir dan servis pada Gedung Pola lantai semi basement menggunakan material beton sedangkan untuk toilet pada lantai satu sampai lantai tiga menggunakan material keramik.

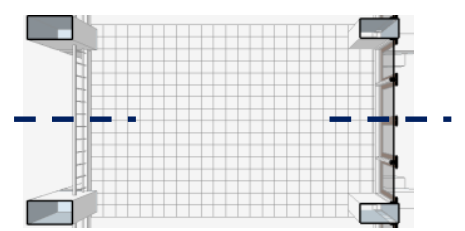

Figur 19: Sumbu Simetri pada Lantai teraso $30 \mathrm{~cm}$ x $30 \mathrm{~cm}$ pada Bangunan Gedung Pola

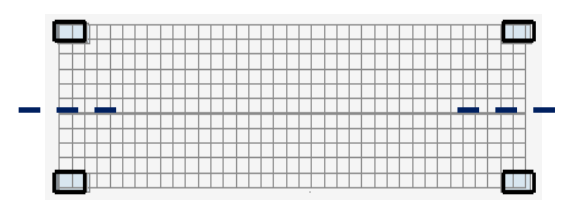

Figur 21: Sumbu Simetri pada Lantai teraso $40 \mathrm{~cm}$ x $40 \mathrm{~cm}$ pada Bangunan Gedung Pola

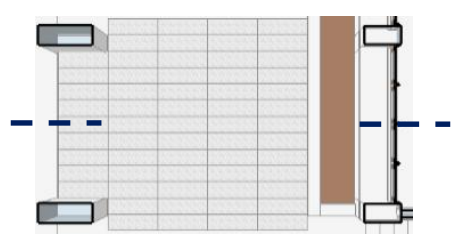

Figur 20: Sumbu Simetri pada Lantai teraso $40 \mathrm{~cm}$ x $120 \mathrm{~cm}$ pada Bangunan Gedung Pola

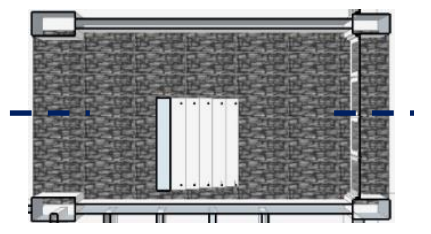

Figur 22: Sumbu Simetri pada Lantai teraso $120 \mathrm{~cm}$ x $50 \mathrm{~cm}$ pada Bangunan Gedung Pola

\section{Denah Ruang}

- Sumbu

Penataan ruang pada Gedung Pola terlihat memiliki sumbu utama memanjang dari depan ke belakang sedangkan sumbu sekunder memanjang dari kiri ke kanan. Ruang-ruang yang tertata seimbang dan rapi mencerminkan Gedung Pola sebagai bangunan monumental.

- Simetri

Tatanan simetri pada ruang Gedung Pola ditunjukan dari bentuk bangunan yang geometrik yaitu persegi panjang. Pada ruang dalam tatanan simetri jelas terlihat dari pembagian ruang, void dan mezzanine serta perletakkan tangga. Jadi, layout denah Gedung Pola merupakan tatanan simetris yang memanjang dari depan ke belakang yang menunjukkan keseimbangan sisi kanan dan kirinya. 
- Hierarki

Ruang tengah pada lantai dua dan ruang tengah lantai tiga bangunan Gedung Pola memiliki bentuk ruang yang berada di tengah antara void yang dapat melihat kegiatan di lantai satu. Penataan dimana ruang yang diapit void di sisi kanan dan kiri menunjukkan bahwa ruang tengah tersebut adalah ruang utama yang memiliki fungsi berbeda dari ruang-ruang lainnya.

- Datum

Datum pada denah ruang Gedung Pola terdapat pada railingnya karena semua lantai terdapat railing yang sama dari lantai satu sampai lantai mezzanine tiga. Irama pada denah terlihat dari pengulangan kolom-kolom bangunan yang sama dari lantai satu sampai dengan lantai mezzanine tiga.

Tampilan Bangunan

- Sumbu

Sumbu pada tampilan Gedung Pola ditunjukkan dari penataan kolomkolom yang seimbang kiri dan kanan begitu juga dengan tatanan bukaannya. Jika dilihat dari tampilan bangunan depan, belakang, dan samping menunjukkan sumbu bangunan berada di tengah Pada tampilan depan bangunan sumbu ditunjukkan dengan tatanan kolom-kolom vertikal dan perletakan bukaan yang seimbang sehingga sumbu bangunan berada di tengah. Pada tampilan belakang bangunan jika dilihat dari penataan bukaan serta kolom-kolom yang menonjol menunjukkan adanya axis pada tampilan samping bangunan Gedung Pola.

- Simetri

Tampilan bangunan sisi depan dan belakang Gedung Pola memiliki elemen seimbang. Pada tampilan depan Gedung Pola mencerikan keseimbangan yang ditunjukkan pada bukaan yang memiliki bentuk sama juga jajaran kolomkolom raksasa yang disusun dengan jarak yang sama sehingga mencerminkan simetris pada tampilan bangunannya. Pada tampilan belakang Gedung Pola memiliki elemen yang seimbang juga yang ditunjukkan pada kesamaan penataan elemen bangunan seperti jendela yang sama.

- Datum dan Irama

Datum pada tampilan fasad bangunan Gedung Pola terletak pada atap yang menaungi keseluruhan bangunan yang menunjukkan bahwa atap bangunan yang menyatukan bangunan Gedung Pola menjadi satu kesatuan yang utuh. Irama yang terdapat pada bangunan terlihat dari kolom-kolom yang menonjol pada sisi samping bangunan Gedung Pola dan sisi depan Gedung Pola, kolomkolom raksasa pada sisi depan bangunan, serta bentuk jendela dan pintu yang berulang pada tiap sisi bangunan Gedung Pola. Hal ini menunjukkan bangunan Gedung Pola yang kaku dan teratur.

\section{PENUTUP}

\subsection{KESIMPULAN}

1. Apa yang dimaksud dengan monumentalitas arsitektur pada penelitian ini?

Monumentalitas dalam arsitektur adalah kualitas atau keadaan sebuah karya arsitektur sebagai sebuah bangunan monumental yang mengandung sebuah pesan atau makna didalamnya yang bertujuan sebagai simbol untuk mengenang sebuah peristiwa sejarah atau tokoh penting yang dapat dilihat dari aspek fisik bangunannya meliputi pola-pola yang terbentuk dari unsur atau elemen pelingkupnya. Sebuah bangunan 
dikatakan monumental jika bangunan tersebut memiliki tatanan yang mencirikan monumentalitas, yaitu memiliki pola tatanan yang simetris dan hierarki. Karakter prinsip penataan yang dapat ditinjau dari lima aspek yaitu tata letak, lingkungan, konstruksi, material, dan elemen-elemennya. Prinsip penataan bangunan monumental dapat terlihat dari kelima aspek tersebut. Monumentalitas pada bangunan Gedung Pola secara fisik ditunjukkan dari penerapan gaya arsitektur Stripped Classicism dimana kolom-kolom besar tanpa ornamen berjajar membentuk sebuah kualitas ruang yang megah. Monumentalitas pada Gedung Pola juga didukung dari nilai sejarah yang dimiliki oleh bangunan Gedung Pola dan kawasannya. Bangunan Gedung Pola yang berada di atas lahan historis saksi kemerdekaan Indonesia 17 Agustus 1945.

2. Bagaimana wujud ekspresi monumentalitas Gedung Pola di Jakarta?

Wujud ekspresi monumentalitas Gedung Pola di Jakarta pada penelitian ini dikaji dari aspek tata letak, lingkungan, konstruksi, material, elemen bangunan, ruang dan fasad bangunannya yang dikaitkan dengan prinsip penataan atau ordering principle. Wujud ekspresi monumentalitas pada bangunan Gedung Pola di Jakarta ditunjukkan dari tata letak bangunan yang menguasi tapak karena letaknya ditengahtengah tapak dan dapat diakses dari semua sisi jalan serta letak massanya yang jauh dari pencapaian sehingga pengamat bangunan dapat merasakan monumentalitasnya dari kejauhan. Bentuk massa bangunan Gedung Pola memiliki sumbu simetri yang kuat pada tata letaknya karena mengambil sumbu mengarah ke posisi rumah Ir. Soekarno sehingga bangunan tidak sejajar dengan jalan utama. Hierarki terlihat dari skala bangunan yang lebih besar dari Tugu Petir. Wujud ekspresi monumentalitas pada bangunan Gedung Pola di Jakarta dari lingkungan ditunjukkan dari posisi Gedung Pola yang berada pada lokasi yang strategis tepatnya dikawasan pusat kota Jakarta. Skala bangunan yang besar serta warnanya yang kontras dengan lingkungannya menjadikan bangunan Gedung Pola monumental. Bangunan Gedung Pola berada di lingkungan yang mayoritas bangunan rendah menjadikan bangunan Gedung Pola sebagai hierarki tertinggi dan menjadi focal point pada lingkungannya. Letak bangunan Gedung Pola yang jauh dari pencapaiannya menunjukkan kepada pengamat bangunan agar dapat merasakan monumentalitas bangunan Gedung Pola dari kejauhan.

Wujud ekspresi monumentalitas pada bangunan Gedung Pola di Jakarta dari sistem konstruksi yaitu penggunaan sistem struktur portal pada Gedung Pola Inovasi struktur juga ditunjukkan pada sistem struktur tangga yang berupa kantilver. Penggunaan sistem struktur yang inovatif menunjukkan keunikan bangunan Gedung Pola sebagai bangunan yang monumental. Rancangan sistem struktur yang unik dan berbeda dengan bangunan-bangunan sekitar menunjukkan hierarki bangunan Gedung Pola lebih tinggi dibanding bangunan sekitarnya dilihat dari sistem strukturnya. Wujud ekspresi monumentalitas pada Gedung Pola di Jakarta dari aspek materialnya adalah dominansi oleh material beton menunjukkan bahwa beton sebagai material yang memiliki hierarki tertinggi pada bangunan Gedung Pola. Penggunaan material beton pada Gedung Pola bertujuan untuk memberikan citra bangunan modern dan tahan lama agar monumentalitas Gedung Pola dapat bertahan lama agar tetap dikenang oleh masyarakat. Wujud ekspresi monumentalitas pada bangunan Gedung Pola di Jakarta dilihat dari elemen-elemennya adalah kuatnya bentuk geometri dengan tatanan sumbu simetri yang kuat pada elemen bangunan Gedung Pola yang terlihat dari pola plafon, railing, pola lantai, jendela, dan pintu. Bentuk elemen-elemen pada bangunan Gedung Pola juga mencerminkan elemen garis vertikal yang kuat. 
Wujud ekspresi monumentalitas Gedung Pola dilihat dari ruang ditunjukkan dari bentuk ruang Gedung Pola yang geometris dan memiliki tatanan sumbu simetris dengan penataan ruang yang seimbang. Penataan void dan ruang-ruang pada Gedung Pola yang menunjukkan hierarki ruang yang tinggi pada ruang tengah lantai satu, ruang tengah lantai dua, ruang tengah lantai tiga. Wujud ekspresi monumentalitas Gedung Pola dilihat dari tampilan bangunan ditunjukkan dari Gedung Pola yang memiliki sumbu simetris karena penataan yang seimbang antara fasad depan dan belakang juga fasad samping kiri dan kanannya. Keseimbangan penataan tampilan bangunan terlihat dari irama pada penataan elemen pelinkupnya. Adanya kolomkolom raksasa pada tampilan depan bangunan Gedung Pola menunjukkan hierarki sisi depan sebagai area penerima utama.

3. Elemen geometrik apa yang mendukung terciptanya ekspresi monumentalitas pada Gedung Pola di Jakarta?

Elemen geometrik yang mendukung terciptanya ekspresi monumentalitas pada Gedung Pola di Jakarta adalah elemen geometrik bujur sangkar. Elemen geometrik bujur sangkar tersebut dapat mendukung monumentalitas Gedung Pola dengan garis sebagai elemen penyusun monumentalitasnya dengan penataan yang berulang menunjukkan irama bangunan Gedung Pola yang statis dan seimbang. Elemen geometris yang dimaksud adala kolom-kolom pada bentuk tampilan dan ruang dalam Gedung Pola. Kolom-kolom raksasa pada tampilan bangunan Gedung Pola yang menonjol dan kolom-kolom pada ruang dalam Gedung Pola dengan bentuknya yang geometri persegi panjang dengan bentuk ramping dan polos juga skala dan dimensinya yang besar tersebut mendukung terciptanya ekspresi monumentalitas pada Gedung Pola.

\subsection{SARAN}

Saran penulis kepada pengelola dan pemerintah adalah untuk terus menjaga dan merawat keoriginalitasan bangunan Gedung Pola, karena melalui penelitian ini, penulis mempelajari bahwa bangunan ini tidak hanya kaya dengan cerita sejarah Indonesia dan Nation Building, tapi bangunan ini juga dapat menjadi contoh bagi sarana pembelajaran objek bangunan monumental yang dirancang tidak hanya berdasarkan arsitektur modern yang sudah melakukan adaptasi dengan lingkungan sekitar, tetapi juga lebih jauh setiap rancangannya didukung oleh teori monumentalitas arsitektur dan ordering principle yang dimana tidak semua bangunan menggunakan dua teori diatas sebagai pembentukan proporsi bangunan yang indah.

\section{DAFTAR PUSTAKA}

\section{Sumber Buku}

Ardhiati, Yuke. 2005. Bung Karno Sang Arsitek: Kajian Artistik Karya Arsitektur, Tata Ruang Kota, Interior, Kria, Simbol, Mode Busana, dan Teks Pidato 1926-1965. Komunitas Bambu: Depok.

Ardhiati, Yuke. 2013. Bung Karno Dalam "Panggung Indonesia”. Wastu Adicitta Press: Jakarta. Ashihara, Yoshinobu. 1970. Exterior Design in Architecture. Van Nostrand Reinhold: USA.

Broadbent, Geoffrey. 1980. Sign Symbol in Architecture. John Willey \& Sons: London.

Ching, Francis D.K. 2008. Arsitektur: Bentuk, Ruang, dan Tatanan Edisi Ketiga. Erlangga: Jakarta.

Evensen, Thomas Thiis. 1987. Archetypes in Architecture. Norwegian University Press: New York.

Krier, Rob. 2001. Komposisi Arsitektur. Erlangga: Jakarta. 
Musgrove, John (eds.). 1987. Sir Banister Fletcher's "A History of Architecture”. 19th ed. CBS Publisher and Distributors: Delhi.

Odang, Sri Astuti SA, dkk. 1992. Arsitektur dan Karyanya F. Silaban dalam Konsep dan Karya. Nova: Bandung.

PDA. 2012. Tegang Bentang. Gramedia: Jakarta.

Salura, Purnama. 2010. Arsitektur yang Membodohkan. Cipta Sastra Salura: Bandung.

Sumalyo, Yulianto. 1997. Arsitektur Modern Akhir Abad XIX dan Abad XX. Gadjah Mada University Press: Yogyakarta.

Zucker, Paul (eds.). 1944. New Architecture and City Planning. Philosophical Library: New York.

\section{Tesis dan Disertasi}

Knapp, A. Bernard. 2009. Monumental Architecture, Identity and Memory. Glasglow, Skotlandia. University of Glasgow.

\section{Jurnal}

Jk, James Renwick. 1846. Ordering Principles Activity, Journal

\section{Skripsi}

Ariwibowo, Irvan. 2007. Tinjauan Bentuk dan Makna Monumen Yogya Kembali. Universitas Katolik Parahyangan: Bandung.

Dania. 2010. Penurunan Monumentalitas Istana Bogor akibat ketidakseimbangan elemen fisik pada aksis Jalan Sudirman : kajian tentang keseimbangan proporsi elemen fisik dan building pada ruang Jalan Sudirman. Universitas Katolik Parahyangan: Bandung.

Sukarsana, Putu Gede. 1997. Aspek Fisik dan Simbolis Arsitektur Monumen Suatu Tinjauan Terhadap Konsep Perencanaan Manda Garuda Wisnu Kencana-Bali. Universitas Katolik Parahyangan: Bandung.

Ferdian. 2001. Monumen Nasional dan Taman Medan Monumen Nasional (Silang Monas) sebagai Landmark Kota Jakarta. Universitas Katolik Parahyangan: Bandung. 